\section{Saúde reprodutiva: uma contribuição para avaliação de biblioteca virtual}

\author{
Reproductive health: a contribution to \\ the evaluation of a virtual library
}

\footnotetext{
1 Faculdade de Saúde Pública, Universidade de São Paulo, São Paulo, Brasil. 2 Escola de Comunicações $e$ Artes, Universidade de São Paulo, São Paulo, Brasil.

Correspondência

M. C. A. Alvarez

Biblioteca: Centro de Informação e Referência em Saúde Pública, Faculdade de Saúde Pública, Universidade de São Paulo

Av. Dr. Arnaldo 715,

São Paulo, $S P$

01246-904, Brasil.

malvarez@usp.br
}

\begin{abstract}
Virtual libraries have been implemented in an attempt to organize scientific information found in the Internet, including the Biblioteca Virtual de Saúde Reprodutiva (BVSR), or Virtual Library on Reproductive Health. The aim is to provide quality information to researchers in the reproductive health field. The current study evaluates the use of the BVSR, emphasizing the users' expectations, difficulties, and suggestions. The study adopted a qualitative methodology. The focus group technique was applied to Internet chat groups through which reproductive health researchers communicated. Users expressed their expectations regarding information, highlighting the lack of time and the need to quickly obtain precise data. Use of virtual libraries for research increases where there is more trust in the institutions responsible for maintaining them. Researchers sug gested the following: greater dissemination of the BVSR, publication of an electronic newsletter, and creation of a communications channel between the BVSR and users in order to foster intelligent collective communication.
\end{abstract}

Reproductive Health; Virtual Libraries; Access to Information
Maria do Carmo Avamilano Alvarez 1

Angela Maria Belloni Cuenca ${ }^{1}$

Daisy Pires Noronha 2

Néia Schor 1

\section{Introdução}

O excesso de informação propiciado pela internet tem demandado dos profissionais da ciência da informação, biblioteconomia e informática soluções para oferecer informações validadas às comunidades acadêmicas e científicas de forma rápida e eficaz. Uma delas foi a implantação de bibliotecas virtuais, que, embora com várias denominações - biblioteca eletrônica, digital -, são espaços na internet nos quais o conhecimento é registrado, organizado, armazenado e disponibilizado em formato eletrônico e acessível de forma universal 1. Elas atuam como buscadores de informações, a exemplo do Google (http://www. google.com.br), porém voltadas aos conteúdos especializados dos sites da rede. As bibliotecas virtuais têm proliferado no Brasil em diversas plataformas, abrangendo temáticas específicas.

Na área da saúde, podem ser destacadas duas iniciativas: o projeto do Centro Latino-Americano e do Caribe de Informação em Ciências da Saúde (BIREME), com as bibliotecas virtuais em saúde, implantada em 1998 e que atualmente abrange países da América Latina e do Caribe, agregando temáticas como saúde mental, saúde pública, história da saúde, psicologia, adolescência, entre outras. Outra iniciativa foi o PROSSIGA (Programa Informação para a Pesquisa), projeto iniciado em 1995 e atualmente ligado ao Instituto Brasileiro de Informação em Ciência e Tecnologia (IBICT), com bibliotecas virtuais 
temáticas, destacando as ciências sociais. Uma delas, que também é ligada à área da saúde, é a Biblioteca Virtual de Saúde Reprodutiva (BVSR: http://www.prossiga.br/fsp_usp/saudereprodutiva), criada em 1998, mediante a parceria entre o Conselho Nacional de Desenvolvimento Científico e Tecnológico (CNPq) e a Faculdade de Saúde Pública da Universidade de São Paulo (FSP/USP), por meio de seu Departamento de Saúde Materno-Infantil e sua biblioteca. A BVSR agrega cerca de dois mil sites ativos e atende uma comunidade formada principalmente por pesquisadores, profissionais da saúde, professores e estudantes interessados em assuntos relativos a saúde reprodutiva 2 .

Estudos sobre bibliotecas virtuais, principalmente de avaliações de uso, são recentes e abrangem poucas investigações críticas.

O objetivo deste artigo é apresentar um estudo de avaliação de uso da BVSR, destacando as expectativas, dificuldades e sugestões dos seus usuários, levantadas por meio de grupos focais on-line.

\section{Método}

O método adotado foi de natureza qualitativa com abordagem exploratória, utilizando-se a técnica de grupo focal, aplicada através de salas de bate-papo na internet (chat).

A escolha dessa técnica de pesquisa, aplicada pela internet para avaliar uma biblioteca virtual, foi com vistas a conferir a pesquisa no setting natural, ou seja, no próprio ambiente dos sujeitos, e para testar a técnica nesse novo ambiente comunicacional.

Alguns trabalhos serviram de suporte para essa escolha, como os de Chase \& Alvarez ${ }^{3}$, que compararam o processo envolvido no modo eletrônico com o modo face-a-face de grupo focal e sua aplicação na área da ciência da informação; Krueger \& Casey ${ }^{4}$, que colocaram a possibilidade da aplicação do grupo focal pelo meio eletrônico; Crowley 5 , que apontou as vantagens do grupo focal eletrônico; O'Connor \& Madge 6, que levantaram as dificuldades de interpretar os silêncios e ordenar as idéias nas reuniões on-line; e Clapper \& Massey 7 , que apontaram como principal dificuldade a falta de expressões não-verbais nas reuniões on-line.

Os sujeitos da pesquisa foram 14 pesquisadores da área da saúde reprodutiva, identificados em vinte instituições brasileiras ligadas à área. Para identificá-los, foram contatados, por telefone e/ou correio eletrônico, 58 pesquisadores, usuários dessa biblioteca virtual, dos quais 44 responderam ao convite. Destes, 17 confirma- ram o interesse em participar e 14 participaram efetivamente.

A coleta de dados foi obtida por meio dos diálogos digitados durante os encontros realizados nas salas de bate-papo. Para esse fim, foram utilizados os recursos: programa Internet Relay Chat, disponível no serviço Ponto de Encontro do PROSSIGA, e a sala de bate-papo disponibilizada pela Divisão de Engenharia Civil do Instituto de Pesquisas Tecnológicas (IPT). Os encontros ocorreram em julho de 2003 (dia 3) e julho de 2004 (dias 12 e 14), com duração de 60 minutos cada. Além dos pesquisadores, contou-se com a participação de um moderador (autor da pesquisa) e um observador (bibliotecário especialista em saúde reprodutiva).

Em cada encontro, foram aplicadas seis questões abertas, com a finalidade de levantar sugestões para melhorar a comunicação entre a BVSR e os seus usuários. As questões foram claras, precisas e breves (Tabela 1), como orientam os autores Chase \& Alvarez ${ }^{3}$, e apresentadas num contexto do geral para o específico. Essas questões passaram por seleção e avaliação no pré-teste com um grupo composto por docentes e alunos de pósgraduação da FSP/USP.

Os dados registrados dos encontros nas salas de bate-papo foram analisados pelo moderador e classificados, primeiramente, de forma ampla quanto aos pontos abordados e, posteriormente, de forma mais pontual, verificando as opiniões dos participantes observadas durante as reuniões.

Para o tratamento dos dados, foram utilizadas técnicas de análise de conteúdo numa abordagem exploratória, baseadas em trabalhos de pesquisa qualitativa ${ }^{8,9}$. Foram então levantadas sugestões que são o objeto de análise do presente trabalho.

Esta pesquisa foi aprovada pelo Comitê de Ética da FSP/USP e observou as normas para pesquisas envolvendo seres humanos estabelecidas pela Resolução no. 196/96 do Conselho Nacional de Saúde do Ministério da Saúde.

\section{Resultados e discussão}

\section{Expectativas do pesquisador em relação à informação da Biblioteca Virtual de Saúde Reprodutiva}

Os pesquisadores esperam encontrar num site especializado em saúde reprodutiva informações na forma de textos completos, como artigos científicos, dissertações, teses e demais publicações sobre a temática. Consideram importantes: um espaço de encontro entre instituições, pessoas 
Questões aplicadas em cada encontro realizado nas salas de bate-papo, com a finalidade de colher sugestões para melhorar a comunicação entre a Biblioteca Virtual de Saúde Reprodutiva e os seus usuários.

\section{Questões}

1. Como pesquisador na área da saúde reprodutiva, o que espera encontrar numa biblioteca virtual?

2. Normalmente, quando entra numa biblioteca virtual ou sites, como você faz para iniciar uma pesquisa? Entra na caixa de busca? Procura pelos itens na página principal?

3. Qual sua opinião sobre os resultados da pesquisa encontrados na Biblioteca Virtual de Saúde Reprodutiva?

4. O que poderia ser modificado no site da Biblioteca Virtual de Saúde Reprodutiva para ajudar na pesquisa ou melhorá-la?

5. Como está hoje, parece fácil entrar em contato com a equipe que trabalha na Biblioteca Virtual de Saúde Reprodutiva, seja por e-mail, formulário ou telefone?

6. Sugira duas mudanças que poderiam ser feitas no site da Biblioteca Virtual de Saúde Reprodutiva para melhorar a comunicação

interessadas na temática, lista de pesquisadores, centros e organizações militantes na área, imagens para ilustrar trabalhos, dados estatísticos, tabelas e gráficos, acesso a bases de dados, catálogos de bibliotecas, divulgação de eventos e fóruns permanentes. Verifica-se que a grande necessidade é encontrar material bibliográfico como apoio às suas pesquisas, além de dados estatísticos. Os esclarecimentos de dúvidas de forma personalizada também foram apontados como importante serviço demandado pela comunidade estudada. Alguns exemplos de respostas:

“Sempre tenho muitas expectativas... É claro que quero encontrar tudo que desejo e nem sempre é possivel. No geral, porém, tenho conseguido ótimas informações no site".

"A minha expectativa é que, por ser um site especializado em saúde reprodutiva, eu vá encontrar materiais que eu preciso no trabalho".

“...textos, pesquisas relacionadas à temática, espaço de encontro entre instituições e pessoas interessadas em determinado assunto".

\section{- Organização do site com base na demanda}

A biblioteca virtual, sendo um "agregado de informações" 10, deve oferecer serviços, divulgá-los à comunidade e, periodicamente, identificar as demandas para se adaptar às novas necessidades. É necessário rever a lógica da comunicação nessas bibliotecas, baseando-se na oferta de informações, sem considerar a demanda. É preciso saber que tipo de informação é importante para os usuários. Por outro lado, sendo uma biblioteca, deve responsabilizar-se pela preservação da memória digital, caso contrário, esta informação poderá se perder.

\section{- Economia de tempo do pesquisador}

Outro aspecto levantado pelos pesquisadores foi o fator tempo. Desde os contatos telefônicos e por correio eletrônico, percebeu-se a constante falta de tempo para participação nesse tipo de serviço. Nas salas de bate-papo, freqüentemente apareceram expressões referentes à disponibilidade de tempo, explicitamente ou implicitamente, indicando uma das preocupações do grupo. Foi unânime a necessidade de poderem contar com um site ágil para não perderem tempo, conforme exemplos a seguir: “...acho que as BVs e portais costumam buscar interação com o usuário, mas percebo que não tem ocorrido, talvez por falta de tempo das pessoas"; “...quando pensamos em internet queremos tudo muito rápido...”; “o nosso problema foi a tecnologia não ir tão rápido quanto o nosso pensamento e vontade de falar"; "nunca tive paciência para me comunicar no MSN"; "as procuras são demoradas"; "ninguém quer gastar tempo para aprender como meios eletrônicos funcionam" e “...perde-se muito tempo".

Rifkin 11 coloca as transformações que estão ocorrendo na economia ciberespacial emergente, que está deslocando todo o tempo livre remanescente dos indivíduos para a órbita comercial. Até mesmo as relações humanas estão se transformando em commodities, ou seja, sendo absorvidas pelo mercado. As máquinas de fax, email, telefones celulares, os mercados comerciais 24 horas, caixas eletrônicos permanentemente abertos, atraem a atenção das pessoas, preenchendo as consciências, ocupando muitos dos pensamentos e tirando a maior parte do tempo de folga.

A economia baseada em rede aumenta a velocidade das conexões, tornando a vida mais conveniente, transformando muitas coisas em 
serviço, mas, por outro lado, as pessoas sentemse como se não tivessem tempo para si mesmas, porque a enorme proliferação de serviços só aumenta a diversidade, o ritmo e o fluxo das atividades transformadas em commodities 11 .

O excesso de informação disponível atualmente também aumenta a ansiedade nas pessoas, sobretudo nos pesquisadores, cujo objeto de trabalho é a informação. Eles precisam selecioná-las e processá-las, transformando-as em novas informações. Esse procedimento faz parte da rotina dos pesquisadores e o problema transpareceu nos grupos focais.

\section{Importância da biblioteca virtual como fonte de dados confiáveis}

Foi possível identificar familiaridade dos pesquisadores na utilização da internet, inclusive com detalhamento de procedimentos de busca de acordo com suas necessidades de pesquisa. Algumas expressões empregadas ilustram essa consideração: "operador booleano", "caixa de busca”, "home-page”, "ferramenta Google”, “descritores" " "base de dados LILACS, MEDLINE" entre outras. Portanto, os pesquisadores mostraramse orientados no uso das tecnologias de informação e comunicação: “...não consegui chegar ao assunto desejado no search do próprio site $e$ precisei recorrer ao Google”; “...às vezes o mapa do site ajuda" e “...talvez seja problema no meu servidor...".

Justifica-se esse achado pelo fato de essa comunidade de pesquisadores, amostra de sujeitos utilizada, pertencer a uma elite, incluída no mundo digital, propiciado pelas universidades. Trata-se de um coletivo politizado e dinâmico, haja vista a posição progressista das participações brasileiras em eventos internacionais desta área, como a Conferência Internacional sobre População e Desenvolvimento, realizada no Cairo, Egito, em 199412 e a Conferência da Mulher em Pequim, China, além de no evento Cairo +5, ocorrido na Assembléia Geral da Organização das Nações Unidas (ONU) em Nova York, Estados Unidos, em 199913.

Quanto à confiabilidade das informações da BVSR, verificou-se que o usuário certifica-se sobre a autoridade da fonte, ou seja, identifica a mantenedora para utilizar a informação. Além disso, a forma como as informações estão estruturadas no site são importantes para permitir ao usuário chegar às informações intuitivamente 14 .

Um pesquisador se posicionou: "Costumo preferir artigos publicados que já passaram por revisão de pares e nesse caso uso as bases tradicionais (BIREME, PubMed etc.)".
Este mesmo pesquisador depois completou que "uma das principais dificuldades de quem quer fazer pesquisa bibliográfica na internet é saber que fontes são confiáveis" e acrescentou uma sugestão dizendo que a "viagem" num site precisa ter volta, pois "as possibilidades de itinerários - links que se abrem sucessivamente - são quase infinitas".

Os critérios de qualidade a serem atribuídos a um site são similares aos que auxiliam na avaliação da informação impressa, ou seja: credibilidade, conteúdo, apresentação, links, design, privacidade e proteção dos dados, política editorial, interatividade e anúncios. Acrescente-se a esses a disponibilidade de mecanismo de busca, legenda com a atualização do site e dados de direito autoral 15. Eysenbach \& Köhler 16 destacaram que os usuários procuram e avaliam informações pela credibilidade da fonte, pelo design profissional, pelo toque oficial ou científico, língua e facilidade de uso. Estes autores também concluíram que pouquíssimos usuários anotaram ou se lembravam dos sites utilizados para recuperação de informações. Isso pode também ter ocorrido com os usuários da BVSR, que acessam uma vez e depois esquecem o endereço para retornarem.

Um dos participantes do grupo focal apresentou o problema da desatualização dos sites, que contribui para diminuir a credibilidade nas bibliotecas virtuais. Atualmente, a BVSR conta com equipe que trabalha na sua atualização e manutenção, mas é necessário implementar ações adicionais para garantir a estabilidade $\mathrm{e}$ seletividade dos sites desatualizados.

\section{Sugestões levantadas pelos pesquisadores sobre a Biblioteca Virtual de Saúde Reprodutiva}

\section{- Boletins eletrônicos}

As sugestões levantadas são consideradas muito importantes à medida que demonstram falhas na BVSR ou pontos negativos. Uma delas foi a necessidade de maior divulgação das bibliotecas virtuais como fontes confiáveis de recuperação da informação. A edição de boletins eletrônicos foi apontada como importante para esse fim.

Observa-se que a divulgação na BVSR ocorre, pois, quando são lançados números novos do boletim e enviados para os endereços eletrônicos dos usuários, o número de acessos aumenta. Alguns cuidados, porém, devem ser tomados, como: manter a periodicidade dos boletins regular, mas com intervalo de tempo que não incomode o usuário; torná-los esteticamente atraentes e com informações adequadas para quem os utiliza. 


\section{- Destaques de informações}

Outro aspecto abordado foi quanto aos "destaques” na BVSR. Trata-se de área no site destinada a oferecer sites com informações que estão na mídia, em geral, televisão, jornais, campanhas, entre outras. Questiona-se se as informações oferecidas nas bibliotecas virtuais têm de estar desprendidas da repetição com a mídia para evitar a comunicação "tautológica”, que é uma junção de autismo com repetição 17. Adotando a sugestão de Sfez 17, é preciso fornecer bases para permitir a interpretação da informação e promover o distanciamento entre o emissor e o receptor na avaliação da mensagem. Assim, a sugestão seria, valendo-se dos assuntos emergentes na mídia, criar um espaço para discussão na biblioteca virtual, procurando colocar informações que provoquem reação do público.

\section{- Apresentação da página principal}

Quanto à apresentação da página principal da BVSR, foi sugerido pelos participantes do grupo focal sua divisão em quatro ou cinco blocos de assuntos, dentro da área da saúde reprodutiva, para que as buscas possam ser feitas pelas especialidades, e não com abrangência geral. Isto já ocorre em outras bibliotecas virtuais, como a Biblioteca Virtual de Saúde Pública (BVS-SP), citada anteriormente, que é organizada em 29 grupos temáticos, disponíveis no site para buscas. Essa sugestão pode ser viabilizada na BVSR, com a criação de uma nova página principal, com a divisão por grandes assuntos do âmbito da área de saúde reprodutiva.

Foram os seguintes os discursos apresentados: fazer um boletim eletrônico, divulgar a BVSR para os pesquisadores, modificar o site, canalizando-o para públicos específicos; organizar discussões, possibilitar a inclusão de trabalhos de pesquisadores no site, integrar-se a outras bases de dados, atualizar informações no site.

Segundo Rosa Maria Villares de Souza Berto (informação obtida em entrevista por chat; http://www.ipt.br/tecnologia/chat, acessado em 13/Jul/2004), especialista em Marketing e Informação Tecnológica, o aspecto visual de um portal deve ser pensado tendo em vista o públicoalvo, mas segmentos específicos, como adolescentes, terceira-idade, podem requerer alguma criatividade e ousadia na organização visual das páginas. A pesquisadora também informou que a tendência visual está em páginas mais "limpas" e focadas e que os portais devem garantir aos usuários interatividade e linguagem adequada.

\section{- Parcerias}

Colocada a questão das parcerias nas bibliotecas virtuais, foi destacada sua importância para evitar a duplicação da informação. As bibliotecas virtuais existem em virtude das parcerias entre instituições congêneres que permitem, além da garantia da credibilidade, informação validada e recursos.

\section{- Busca integrada}

Outra sugestão para otimização da busca na BVSR foi a integração dos itens do site com as bases de textos completos. Isso já ocorre com as que adotam uma tecnologia diferenciada, como as da BIREME, que utilizam metodologia comum e compatível para fazer as integrações de bases de dados, diretório de links, periódicos eletrônicos, diretórios de pesquisadores etc. Dessa forma, é possível utilizar um programa de metabusca que pesquisa simultaneamente em diferentes bases de dados. A BVSR foi concebida para ser um diretório de links, com alguns serviços acoplados para os usuários. A viabilidade de serem integrados sites e bases de dados dependerá de um novo software.

\section{- Canal de comunicação}

Outra idéia foi tornar disponível um canal de comunicação para o usuário deixar sugestões de assuntos, melhorando a qualidade da BVSR quanto à participação ativa dos usuários. Além de indicações temáticas, poderiam ser indicados novos sites, assim como os inativos e obsoletos. Os participantes acrescentaram que isto criaria um clima de debate, com a possibilidade de participação bastante interessante: "Acho que quanto mais 'vivo' o site estiver, provocativo, atual (...) mais ele se torna interessante e dá mais vontade de consultar".

As discussões prosseguiram com a seguinte consideração do moderador: "Fico pensando se as pessoas já entendem a internet como uma forma de se manifestarem, opinarem, aprenderem, participarem". A partir dela foram apresentadas idéias interessantes, como: “Às vezes falta tempo, mas é também falha de muitos sites que apenas informam e não dão a oportunidade de expressão"; "Acho que os meios eletrônicos têm muita dificuldade de uso, e ninguém quer gastar tempo para aprender como meios eletrônicos complexos funcionam"; "Uma grande parte das pessoas no interior dos estados não possuem computadores e não sabem ao menos como entrar na internet, estamos falando de Brasil? País das diferenças" e "Acho que é uma fase de transição (...) a cultura 
está mudando (...) é preciso dar um tempo para isso...".

A comunicação está caminhando da cultura de massas (comunicação "um-todos" de Lévy 18) para o surgimento da cultura da virtualidade real 19 ou, na opinião de Lévy ${ }^{20}$, para o pólo informático-mediático (comunicação "todos-todos”), ou ainda, para a comunicação em rede ou eletrônica 21.

Na cultura de massa as mentes absorvem as mensagens de forma associativa/lírica, sem envolver esforço psicológico ou raciocínio de análise, sem feedback. A nova fase caracteriza-se pela possibilidade de compartilhamento dos hipertextos entre os atores da comunicação, o que promoverá novas formas de inteligência coletiva mais flexíveis e democráticas, fundadas na reciprocidade. Com a internet, surgiu um sistema de comunicação interativo, resgatando a mentalidade da tipografia e a recuperação do discurso racional.

A comunicação informático-mediática também está nas mãos de grandes provedores que já dominavam a comunicação na mídia, como a Rede Globo de Televisão, Universo Online, com principais revistas, jornais etc. É preciso ter consciência de que os provedores sem fins lucrativos, como os das universidades, têm a responsabilidade de promover com qualidade esta comunicação "todos-todos”, com serviços expandidos para o público heterogêneo da internet. Caso contrário, a interação comunicacional das novas gerações ficará no âmbito de escolher quem ganhará o "Big Brother" ou quem será a "Princesinha do Verão" (programas de entretenimento da televisão) e não em discussões e avaliações de serviços e informações. É preciso promover a construção de coletivos inteligentes.

As bibliotecas virtuais devem atuar na preservação e divulgação da informação para beneficiar o conhecimento na cibercultura. Este segmento, segundo Monteiro 22, é o que mais se beneficiará com o mundo virtual, dada a disponibilidade e facilidade de acesso.

A sociedade deve ser preparada para ter uma visão crítica, fazer uma desconstrução, buscando significados escondidos ou subentendidos numa informação, seja textual, imagética, sonora; mostrando contradições internas e falando dos sentidos contra-intencionados ${ }^{8}$. Todas as pessoas têm competências para compartilhar e desenvolver o espaço do saber e a inteligência coletiva 23.

Para Fassler 24, o abismo digital que se formou na sociedade deve-se ao fato de as tecnologias terem se desenvolvido paralelamente às ciências sociais e à teoria da comunicação. A tecnologia não interagiu com as humanidades durante muito tempo. Dessa forma, criou-se um coletivo pensante, envolvido com questões educacionais e sociais, desvinculado do outro coletivo pensante envolvido com as tecnologias nas ciências exatas. No encontro dessas duas categorias, desencadeado pela internet, a população tomou contato com as tecnologias sem terem desenvolvido senso crítico a respeito, as idéias não foram trabalhadas, não houve tempo para discussão se essa ferramenta era boa ou não, a velocidade se sobrepôs ao raciocínio e uma elite mergulhou de cabeça no mundo virtual, sem ter preparado outras classes sociais.

O resultado disso é a exaustividade do oferecimento de informações e o pouco tempo e escassez de formação cognitiva para aflorar o conhecimento real. Para Lévy 23, a formação cognitiva é a junção da competência, desenvolvida pelas relações com as coisas; o conhecimento desenvolvido das relações com os signos e informações, e o saber, desenvolvido através das relações com os outros.

A sociedade está inserida na cultura de massas, que constitui um empecilho à passagem para a cultura interativa. A massificação da cultura separa os bens culturais pelo seu suposto valor de mercado, cria a ilusão de que todos têm acesso aos mesmos bens, inventa um espectador "médio" por meio do fornecimento de informações já conhecidas para não perturbá-lo e define a cultura como lazer e entretenimento 25 .

Uma colocação interessante de um participante das reuniões ressalta o costume trazido da comunicação "um-todos" da mídia quando diz: "talvez não estejamos acostumados a usar a internet para interagir com outras pessoas ou debater idéias". Estará a internet sendo usada somente como a comunicação "um-um" (e-mail) ou umtodos ("websites")? Será que o coletivo conseguirá se desprender da cultura que o categoriza pelo poder econômico, informa-o de acordo com interesses também econômicos, dispersa a sua atenção e diminui a sua capacidade de pensar, infantiliza-o e o torna passivo?

\section{- Público abrangente}

Quanto ao público que abrange, foi sugerido que a BVSR trabalhe com segmentos de usuários, conforme o depoimento seguinte: "Público leigo e escolares, divulgando os sites teens do IBGE $e$ do MS; portal de periódicos da CAPES e PubMed para pesquisadores de ONGs e universidades estes poderosos instrumentos encontram-se ainda subutilizados e pouco conhecidos".

A disponibilização de informações on-line para públicos diferenciados já ocorre na National Library of Medicine (NLM; http://www.nlm. nih.gov) dos Estados Unidos, segmentando as 
categorias: público em geral, profissionais de cuidados da saúde, pesquisadores, bibliotecários e editores. Dessa forma, o usuário recupera informações mais pertinentes às suas necessidades numa linguagem mais adequada ao seu perfil. $\mathrm{O}$ website da NLM foi organizado para segmentos de público, com base nos resultados de testes de uso e de desenhos para sua nova página, realizados com seus usuários.

Verifica-se que as novas gerações, os adolescentes, por exemplo, utilizam a internet intensamente para a comunicação interativa com seus pares. Na sala de bate-papo foi comentado que esse instrumento "é um excelente meio de comunicação, os adolescentes que o digam, 'pendurados' que ficam por horas no MSN". Pode ser que esses jovens estejam mais preparados para usar as novas tecnologias, porém não o estão para o uso efetivo da informação no desenvolvimento de pesquisas e discussões temáticas, e isto só será possível se ocorrer a educação em seu sentido amplo.

Estudos psicológicos e sociológicos estão sendo feitos para avaliar as mudanças causadas por essas novas tecnologias no desenvolvimento cognitivo dos jovens. Alguns resultados apontam que os jovens, assíduos usuários do computador para se comunicarem entre si, desenvolvem estruturas de consciência fragmentadas e transitórias, ocasionando dificuldades de adaptação ao mundo social. Ao mesmo tempo, outros resultados consideram que essa nova consciência será mais flexível, adaptativa e positiva ${ }^{11}$.

Schwartz 26 afirma que os adolescentes interagem com as novas tecnologias de comunicação com naturalidade e que a tendência é de ampliação, ou seja, as novas tecnologias estão se tornando baratas e poderosas; o "adolescente global" irá "desejar" comunicar-se desta forma; usar esse tipo de mídia tende a alterar o comportamento e os valores da pessoa, e estes passarão a ser as competências que o adolescente possuirá para transmitir ao outro, encorajando a inteligência ativa. Se as informações não forem compartilhadas entre as pessoas, elas perdem sua função e alcance social.

A BVSR foi constituída para atender pesquisadores da área, porém observou-se que seu público passou também a ser o adolescente. Isto vai ao encontro da opinião de Delgado-Gómez 27, que observa o aumento do uso das bibliotecas virtuais pelos adolescentes, destacando que, no futuro, esse hábito se tornará mais comum. O adolescente, portanto, é um público mais aberto às comunicações no ciberespaço, devendo ser levado em consideração como um segmento de usuário de bibliotecas virtuais.

\section{Sobre o uso do grupo focal on-line}

O método colaborou com o presente trabalho, destacando-se o uso da técnica do grupo focal, empregada em pesquisas qualitativas, porém num novo formato, o on-line, utilizando internet. Esse formato apresentou pontos favoráveis e desfavoráveis na sua aplicação e na expectativa de resultados, conforme descritos a seguir.

A técnica grupo focal através de salas de bate-papo na internet foi considerada positiva por vários participantes, que consideraram uma experiência nova e interessante, como pode ser observado nas seguintes falas: “...eu gostei muito. Conheço grupos focais 'reais`e achei que esse, virtual, acaba se assemelhando bastante ao outro, desde que as pessoas se sintam à vontade para dar palpite na fala dos demais participantes, concordando ou discordando, ao invés de se restringirem a apenas responder o que é perguntado pelo moderador"; "Achei a experiência interessante. Às vezes um pouco lento o processo, mas de qualquer modo é um excelente meio de comunicação, os adolescentes que o digam, 'pendurados' que ficam por horas no MSN..."; "Eu nunca havia participado, também gostei bastante, achei bastante válido. Eu nunca tive paciência para me comunicar no MSN, como muitos amigos meus, quem sabe agora eu não tente?" e "Nunca tinha tido esta experiência. Achei muito interessante".

A grande facilidade dos grupos focais via internet é a possibilidade de reunir pessoas de vários lugares, acomodados em suas salas, escritórios, em ambientes que lhes são familiares. Isto sem custo de locomoção.

No planejamento do método, a maior dificuldade encontrada foi na localização de uma sala de bate-papo que possibilitasse controle dos usuários, evitando a entrada de pessoas desconhecidas na conversa, que fosse de fácil utilização e permitisse a recuperação dos diálogos de forma sistematizada.

Na organização da agenda das reuniões online, a maior dificuldade foi a falta de tempo dos participantes. Como são pesquisadores, na maioria docentes universitários, ocupados com publicações, pesquisas, aulas, projetos, eventos, não dispunham de agenda para participação conjunta nas salas de bate-papo. Além disso, o fato de a presente pesquisa ter sido realizada em um meio pouco utilizado por eles - salas na internet - gerou certa indecisão na confirmação das agendas. Essas circunstâncias foram apontadas em estudo sobre o uso da internet por docentes da área de saúde pública, na qual o uso de listas de discussão, salas de bate-papo e teleconferências são os recursos menos utilizados pela comuni- 
dade acadêmica brasileira, assim como acontece em outros países ${ }^{28}$. De acordo com esse estudo, as salas de bate-papo (chat, ICQ) são utilizadas por menos de $10 \%$ dessa comunidade, sendo o e-mail o recurso mais utilizado (96,9\%).

Alguns participantes afirmaram que não conseguiam ler o que os demais escreviam, em virtude de a configuração do microcomputador utilizado não ter suas telas atualizadas. Outros enfrentaram a lentidão da rede e obsolescência de equipamentos.

\section{Considerações finais}

Este estudo, além de apresentar sugestões pontuais para um site de divulgação da informação em saúde reprodutiva, propiciou uma reflexão sobre as novas tecnologias de informação e sua relação com pesquisadores, levando a observar a necessidade de se promoverem, periodicamente, estudos com usuários para conhecer qual a sua demanda e perfil. É provável que o usuário da BVSR tenha vários perfis, e a sugestão da segmentação para os diversos públicos deve ser levada em conta na sua reestruturação, incluindo o público adolescente, futuros pesquisadores.

Destaca-se a necessidade levantada nas reuniões de se ter disponível um site que apresente as informações rapidamente, uma vez que a disponibilidade de tempo para os pesquisadores é escassa, ou assim percebida.

A promoção da comunicação "todos-todos” também emergiu como uma necessidade para se obter qualidade na informação, uma vez que, desse modo, obtêm-se idéias, capacitam-se os usuários e divulga-se a BVSR. O controle descentralizado, a comunicação em múltiplas vias e a natureza interativa e aberta da internet fazem das bibliotecas virtuais um instrumento apropriado para promover o pensamento crítico.

A informação em saúde ao alcance da população ou de seus gestores fortalece a promoção da saúde e o desenvolvimento da cidadania, incentiva iniciativas individuais e comunitárias e promove a participação da população nas ações de saúde, mecanismo garantido na Constituição Federal. As bibliotecas virtuais podem se destacar como instrumentos que reforçam grandes possibilidades de participação consciente e democrática da população nessas ações.

O uso do grupo focal via internet pode ser utilizado por pesquisadores, como técnica de coleta de dados, como também pelas equipes das bibliotecas virtuais para se comunicarem entre si e com seus usuários. Sugere-se o uso dos emoticons e MSN para permitir a transmissão dos sentimentos. O baixo custo desses recursos é sua maior vantagem.

Quanto à implementação das sugestões para a BVSR, é necessário o trabalho conjunto de profissionais da informação e especialistas dessa área temática. Cabe aqui ressaltar que, na era da tecnologia da informação, a integração de vários profissionais - da informática, da ciência da informação, da biblioteconomia e, principalmente, profissionais das áreas temáticas a que se destinam as bibliotecas virtuais - é fundamental para a construção e manutenção de fontes de informação na internet que tenham qualidade, credibilidade e sejam acessíveis de forma universal para seus diferentes públicos. 


\section{Resumo}

As bibliotecas virtuais foram implementadas numa tentativa de organizar a informação científica encontrada na internet. Dentre elas, destaca-se a Biblioteca Virtual de Saúde Reprodutiva (BVSR), cujo princípio é oferecer informações com qualidade aos pesquisadores da área da saúde reprodutiva. O objetivo deste trabalho é apresentar um estudo de avaliação de uso da BVSR, destacando as expectativas, dificuldades e sugestões dos seus usuários. Foi utilizado método de natureza qualitativa, com a técnica de grupo focal, aplicada por meio de salas de bate-papo na internet, em pesquisadores da área. Os resultados mostram as expectativas do pesquisador em relação à informação, apontando para discussões relacionadas à falta de tempo e à necessidade de obter a informação com precisão e rapidez. O uso da BVSR para pesquisas é maior de acordo com a confiabilidade das instituições mantenedoras. Algumas sugestões levantadas pelos pesquisadores foram: necessidade de maior divulgação, edição de boletins eletrônicos, disponibilização de um canal de comunicação entre a BVSR e os usuários, a fim de promover a construção de coletivos inteligentes.

Saúde Reprodutiva; Bibliotecas Virtuais; Acesso à Informação

\section{Referências}

1. Centro Latino-Americano e do Caribe de Informação em Ciências da Saúde. Objetivos e funções. http://www.bireme.br/bvs/bireme/P/objetivos. htm (acessado em 22/Nov/2005).

2. França Junior I, Abdalla ERF, Ferraz MLEF, Duque A, Andrade MTD, Siqueira AA. Biblioteca Virtual de Saúde Reprodutiva (BVSR): seus primeiros movimentos [resumo] In: Livro de Resumos do 2o Congresso Brasileiro Ciências Sociais em Saúde. Rio de Janeiro: ABRASCO; 1999. p. 171.

3. Chase L, Alvarez J. Internet research: the role of the focus group. Library \& Information Science Research 2000; 22:357-69.

4. Krueger RA, Casey MA. Focus group: a practical guide for applied research. 3rd Ed. Thousand Oaks: Sage Publications; 2000.

5. Crowley A. Looking for data in all right places (online focus group). PC Week 1996; 13:51-3.

6. O'Connor H, Madge C. Focus group in cyberspace: using the internet for qualitative research. Qualitative Market Research 2003; 6:133-43.

7. Clapper DL, Massey AP. Electronic focus group: a framework for exploration. Information \& Management 1996; 30:43-50.

\section{Colaboradores}

M. C. A. Alvarez planejou e elaborou a pesquisa, organizou e redigiu o texto. A. M. B. Cuenca acompanhou a pesquisa, orientou a organização do texto e participou da revisão do texto. D. P. Noronha colaborou na organização e revisão do texto. N. Schor orientou a pesquisa, sobretudo na utilização do método.

\section{Agradecimentos}

Este trabalho é parte de Dissertação de Mestrado defendida por M. C. A. Alvarez em 2005 na Faculdade de Saúde Pública da Universidade de São Paulo, intitulada A Biblioteca Virtual de Saúde Reprodutiva: Dando Voz ao Usuário.

Agradecemos a Divisão de Engenaria Civil do Instituto de Pesquisas Tecnológicas pelo uso da sala de bate-papo.
8. Turato ER. Tratado de metodologia da pesquisa clínico-qualitativa. Petrópolis: Editora Vozes; 2003

9. Denzin NK, Lincoln YS, editors. Handbook of qualitative research. $2^{\text {nd }}$ Ed. Thousand Oaks: Sage Publications; 2000.

10. Barreto AA. A questão da informação. São Paulo Perspect 1994; 8:3-8.

11. Rifkin J. A era do acesso. São Paulo: Makron Books; 2001

12. Alvarenga AT, Schor N. Contracepção feminina e política pública no Brasil: pontos e contrapontos da proposta oficial. Saúde Soc 1998; 7:87-110.

13. Abracinskas L. Nenhum passo atrás, todos para frente! Jornal da Redesaúde 1999; (18):2-4.

14. Furquim TA. Fatores motivadores de uso de site web: um estudo de caso. Ciênc Inf 2004; 33:48-54.

15. Lopes IL. Novos paradigmas para avaliação da qualidade da informação em saúde recuperada na web. Ciênc Inf 2004; 33:81-90.

16. Eysenbach G, Köhler C. How do consumers search for and appraise health information on the world wide web: qualitative study using focus group, usability tests, and in-depth interviews. BMJ 2002; 324:573-7. 
17. Sfez L. Informação, saber e comunicação. Informare 1996; 2:5-13.

18. Lévy P. O que é o virtual. São Paulo: Editora 34; 1996.

19. Castells M. A sociedade em rede. São Paulo: Editora Paz e Terra; 1999.

20. Lévy P. As tecnologias da inteligência: o futuro do pensamento na era da informática. São Paulo: Editora $34 ; 1993$.

21. Rodrigues AD. Comunicação e cultura: a experiência cultural na era da informação. Lisboa: Editora Presença; 1994.

22. Monteiro SD. Aspectos filosóficos do virtual e as obras simbólicas no ciberespaço. Ciênc Inf 2004; 33:108-16.

23. Lévy P. A inteligência coletiva. 3a Ed. São Paulo: Editora Loyola; 2000.
24. Fassler M. Moments of cyber-modernity: interacting in distributed artificial societies. In: Anais do Simpósio Internacional Universidade e Novas Tecnologias: Impactos e Implicações. São Paulo: Rede Macunaíma do Projeto Alfa; 1998. p. 91-7.

25. Chauí M. Convite à filosofia. 12a Ed. São Paulo: Editora Ática; 2001.

26. Schwartz P. A arte da visão de longo prazo: planejando o futuro em um mundo de incertezas. São Paulo: Best Seller; 2000.

27. Delgado-Gómez AF. Young adults and virtual libraries: a case study. New Library World 2002; 103:277-83.

28. Cuenca AMB, Tanaka ACA. Influência da internet na comunidade acadêmico-científica da área de saúde pública. Rev Saúde Pública 2005; 39:840-6.

Recebido em 19/Fev/2006

Versão final reapresentada em 28/Fev/2007

Aprovado em 11/Abr/2007 